\title{
Controlled modulation of 1D ZnO nano/micro structures: Evaluation of the various effects on the photocatalytic activity
}

\author{
Osman Arslan ${ }^{\mathrm{a}, \mathrm{b}, *}$, Yüksel Abalı ${ }^{\mathrm{a}}$ \\ a Chemistry Department, Celal Bayar University, 45100, Manisa, Turkey \\ b Bilkent University, National Nanotechnology Center (UNAM), Ankara 06800, Turkey
}

\section{A R T I C L E I N F O}

\section{Keywords:}

ZnO nano/microstructures

HMTA

$1 \mathrm{D}$ materials

Photocatalysis

\begin{abstract}
A B S T R A C T
Effects of the concentration, temperature and precursor type on the fabrication of the elongated $\mathrm{ZnO}$ nano/ micro structures were comprehensively investigated. Analytical investigations such as SEM and statistical analysis of the elongated $\mathrm{ZnO}$ nano/micro structures provided wide information about the growth behavior and final geometries. Different temperatures for the $1 \mathrm{D} \mathrm{ZnO}$ formation clearly revealed that hexagonally grown $\mathrm{ZnO}$ nanorods were obtained. Especially low crystal diffraction characteristics at low temperature $\left(55^{\circ} \mathrm{C}\right)$ implied that $\mathrm{ZnO}$ nano/micro rod formation requires some minimum conditions for the formation of an efficient photocatalyst. All XRD investigations together with SEM and TEM supported the ligand ordered elongation conducted by diverse beginning concentrations. Since temperature found as a highly dominant actor for morphology and surface sequence as manifested in crystallinity, morphology and photocatalytic results, we have systematically summarized the growth conditions of the $\mathrm{ZnO}$ nano/micro rods from same precursor.
\end{abstract}

\section{Introduction}

Zinc oxide $(\mathrm{ZnO})$ in its amorf or nano form is a very important commercial material and it is used in commercial paints, as catalyst in rubber processing and UV preventing agent in sunscreen creams and also in many different emerging areas [1-3]. Especially $\mathrm{ZnO}$ thin films and nanostructures are very useful for nanoelectronic applications like solar cells or piezoelectrical applications. It is known that $\mathrm{ZnO}$ has a very wide band gap (3.37 eV) energy as a semiconductor and also has a large exciton binding energy $(60 \mathrm{meV})$. In addition to that, exciton Bohr radius in $\mathrm{ZnO}$ is in the range of 1.4$3.5 \mathrm{~nm}$ [4-6]. As one of the most important morphological modification, one dimensional $\mathrm{ZnO}$ nanowires and nanorods show unique structural one-dimensionality and measurable quantum confinement effects. Therefore it can find also different application areas such as room-temperature ultraviolet (UV) lasers, photodetectors and gas sensors [7-9].

Within the diverse nanostructures of $\mathrm{ZnO}$ one-dimensional $\mathrm{ZnO}$ synthesis has been studied widely due to its facile growth characteristics along the $\mathrm{c}$ axis of the wurtzite crystal, which has a hexagonal unit cell. Since polar faces are electrostatically unstable, (as known like Tasker type III surfaces) \{0001\} planes have the highest energy for further growth. Therefore $\mathrm{c}$ axis of the $\mathrm{ZnO}$ is the fastest growing direction. In case of the kinetically controlled surfaces for example solution-phase syntheses, growth of the $\mathrm{ZnO}$ can be promoted by using ligands that preferentially attach to specific crystal faces. Still, one dimensional $\mathrm{ZnO}$ nanostructures are mostly synthesized by gas phase techniques such as chemical vapor deposition (CVD), chemical vapor transport (CVT) or pulsed laser deposition (PLD) [10-16]. Instead of gas phase reactions, solution based techniques such as hydrothermal or solvothermal methods or chemical precipitation or controlled reflux are highly attractive and don't require high temperatures $\left(<300{ }^{\circ} \mathrm{C}\right)$. This aspect lead us to study synthesis of $\mathrm{ZnO}$ nanorods by using aqueous conditions of by different molecular precursors. $\mathrm{Zn}\left(\mathrm{NO}_{3}\right)_{2} \cdot 6 \mathrm{H}_{2} \mathrm{O}$ as $\mathrm{Zn}$ source and hexamethylene tetramine (HMTA) was selected as ligant for present study. In the literature similar studies of hydrolysis for zinc nitrate $\left[\mathrm{Zn}\left(\mathrm{NO}_{3}\right)_{2}\right.$. $6 \mathrm{H}_{2} \mathrm{O}$ ] in water with the addition of HMTA was also intensively studied [17].

In the present work, we focused to the temperature and concentration effect on the formation of $1 \mathrm{D} \mathrm{ZnO}$ nano/micro structures. By facile and easy to apply synthesis method, $1 \mathrm{D} \mathrm{ZnO}$ structures were fabricated and their compositional, geometrical and photocatalytical features were examined. Obtained 1D structures were analysed by SEM, TEM, XPS and other analytical methods to observe the surface and morphology effects for a general evaluation of the on the formation of the $1 \mathrm{D} \mathrm{ZnO}$ nano/micro structures.

\footnotetext{
* Corresponding author.

E-mail address: arslan@unam.bilkent.edu.tr (O. Arslan).
} 
a

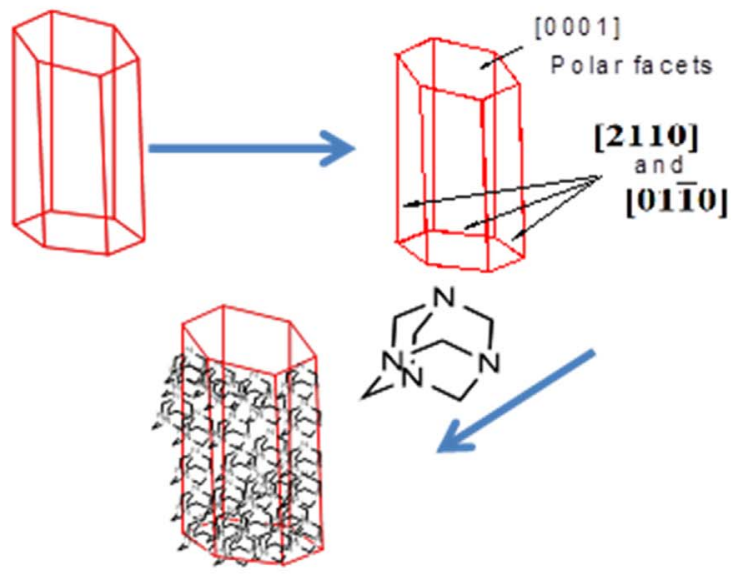

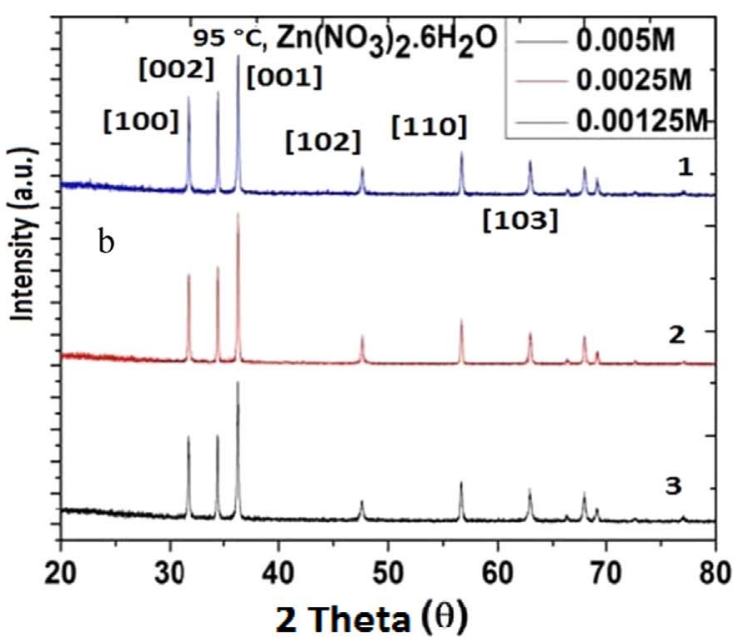

Fig. 1. a) Selective adsorption of HMTA during $\mathrm{ZnO}$ nano/micro rod formation b) XRD patterns of the ZnO nanorods synthesized with different concentrations at $95{ }^{\circ} \mathrm{C}$.

\section{Experimental}

\subsection{Materials}

Zinc nitrate hexahydrate $\left(\mathrm{Zn}\left(\mathrm{NO}_{3}\right)_{2} \cdot 6 \mathrm{H} 2 \mathrm{O}, 98 \%\right.$ purity), hexamethylene tetraamine (HMTA, 99\% purity Alfa Aesar) were used as purchased. Technical EtOH and aceton and deionized water (DI) were used for the washing and drying procedures.

\subsection{General procedure for $\mathrm{ZnO}$ nanorod synthesis}

For the synthesis of the elongated $\mathrm{ZnO}$ structures, both $0.5 \mathrm{M}$ $\mathrm{Zn}\left(\mathrm{NO}_{3}\right)_{2} \cdot 6 \mathrm{H}_{2} \mathrm{O}$ and $0.5 \mathrm{M}$ HMTA stock solutions were prepared and stored. Required amount of the solution from these stock solutions was taken and diluted with water to the $230 \mathrm{ml}$ Teflon beakers. Solution was ultrasonicated for $5 \mathrm{~min}$ and placed into an oil bath which was heated previously to the required temperature. After $24 \mathrm{~h}$ solution was centrifuged and solid structures were washed with EtOH and aceton 2 times. There was no stirring during $24 \mathrm{~h}$. All samples were dried in oven at $110^{\circ} \mathrm{C}$ before the measurements (Fig. S1). List of the assynthesized $1 \mathrm{D} \mathrm{ZnO}$ nanostructures and synthesis conditions were presented in Table $\mathrm{S} 1$.

\subsection{Concentration effect on the $1 \mathrm{D} \mathrm{ZnO}$ synthesis}

Concentration effect on the formation of the $\mathrm{ZnO}$ nanorods from $\mathrm{Zn}\left(\mathrm{NO}_{3}\right)_{2} \cdot 6 \mathrm{H}_{2} \mathrm{O}$ was studied with different $(0.05 \mathrm{M}, 0.025 \mathrm{M}$ and $0.0125 \mathrm{M}) \mathrm{Zn}^{2+} /$ HMTA (1/1) concentrations. General procedure was applied for each sample.

\subsection{Temperature effect on the $1 \mathrm{D} \mathrm{ZnO}$ synthesis}

Temperature variation on the formation of the $1 \mathrm{D} \mathrm{ZnO}$ was studied in different $\left(95^{\circ} \mathrm{C}, 85^{\circ} \mathrm{C}, 75^{\circ} \mathrm{C}\right.$ and $\left.55^{\circ} \mathrm{C}\right)$ temperatures with $0.0125 \mathrm{M}$ concentration for same $\mathrm{Zn}^{2+}$ /HMTA ratios. During synthesis, oil bath temperature arranged very finely $( \pm 1 \mathrm{C})$ and obtained solid structures were prepared as mentioned above.

\subsection{Characterization}

The powder X-ray diffraction (XRD) patterns of as-synthesized and thermally treated $\mathrm{ZnO}$ nanorods were measured with a STOE-STADI MP vertical system in transmission mode using $\mathrm{Cu} \mathrm{K \alpha}(\alpha=0.15406 \mathrm{~nm})$ radiation. FT-IR and SEM analyses were conducted with Perkin ElmerSpectrum 400 and NovaSEM 430 respectively. Samples were placed over a $\mathrm{Cu}$ tape for SEM and sputtered with $5 \mathrm{~nm}$ Au using PECS-682.
UV-visible measurements and nanorod size analysis were carried out using Perkin-Elmer Lambda 950 and Image $\mathrm{J}$ programme respectively. XPS was used for $\mathrm{ZnO}$ nanorod surface analysis. Experiment was performed by X-ray photoelectron spectroscopy (XPS, Thermo Scientific). XPS spectra was obtained by a flood gun charge neutralizer system equipped with a monochromated $\mathrm{Al} \mathrm{Ka} \mathrm{X}$-ray source $(\mathrm{h} v=1486.6 \mathrm{eV}$ ) by using a $400 \mathrm{~mm}$ spot size. TEM investigation was obtained by JEOL-JEM 2100 high-resolution transmission electron microscope using $200 \mathrm{~nm}$ mesh $\mathrm{Cu}$ grids. EtOH solution of $\mathrm{ZnO}$ structures were dropped on $\mathrm{Cu}$ grid and dried at room temperature. No sputtering was applied.

\subsection{Photocatalytic activity evaluation}

The photocatalytic performance of the obtained $1 \mathrm{D} \mathrm{ZnO}$ structures were evaluated based on the degradation reaction of methylene blue (MB) aqueous solution. Before photocatalytic application, blank corrections were made for catalytic activity study. After that, MB solution $\left(1.10^{-4} \mathrm{M}\right)$ was prepared in water and $1 \mathrm{D} \mathrm{ZnO}$ nanorods $(1 \mathrm{mg})$ were dispersed with stirring at $100 \mathrm{rpm}, 5 \mathrm{~min}$. To ensure the adsorption of the methylene blue, solution was stirred with $250 \mathrm{rpm}$ at dark condition (in a closed closet) for $1 \mathrm{~h}$ before the experimental procedure. Subsequently $50 \mathrm{ml}$ solution was irradiated with mercury lamp ( $352 \mathrm{~nm}$, distance $=15 \mathrm{~cm}$ ) and sample aliquots were taken to observe the concentration by UV-vis spectroscopy. The measured absorption values for methylene blue was fitted with an exponential decay (ln $(\mathrm{C} /$ $\mathrm{C}_{0}$ )=-kt) where $\mathrm{t}$ is the exposure time and $\mathrm{k}$ is the decay constant, $\mathrm{C}_{0}$ and $\mathrm{C}$ are the concentrations of methylene blue at the time of 0 (beginning) and t. Particles were centrifuged and separated before the UV-vis measurements. An additional experiment was conducted for the general dye adsorption onto the $\mathrm{ZnO}$ structures in every experiment to avoid the experimental errors.

\section{Results and discussion}

\subsection{General evaluation of the $1 \mathrm{D} \mathrm{ZnO}$ synthesis}

It is widely known that aqueous solutions of easily soluble zinc salts form $\mathrm{Zn}^{2+}$ cations by solvation via water molecules but these conditions differ when dilute solutions are prepared. Because zinc(II) can exist as hydroxyl species such as $\mathrm{ZnOH}_{(\mathrm{aq})}^{+}, \mathrm{Zn}(\mathrm{OH})_{2(\mathrm{aq})}, \mathrm{Zn}(\mathrm{OH})_{3}^{-}{ }_{(\mathrm{aq})}$ and $\mathrm{Zn}(\mathrm{OH})_{4}{ }^{2-}{ }_{\text {(aq) }}$ [18]. Therefore concentration of the prepared solutions must be controlled for these complexes which are dependent on the $\mathrm{pH}$ and solution temperature. When solutions become saturated and solid $\mathrm{ZnO}$ nuclei formation is started, $\mathrm{ZnO}$ crystal can grow more by the diffusion of the available precursors. Furthermore hydroxyl complex 

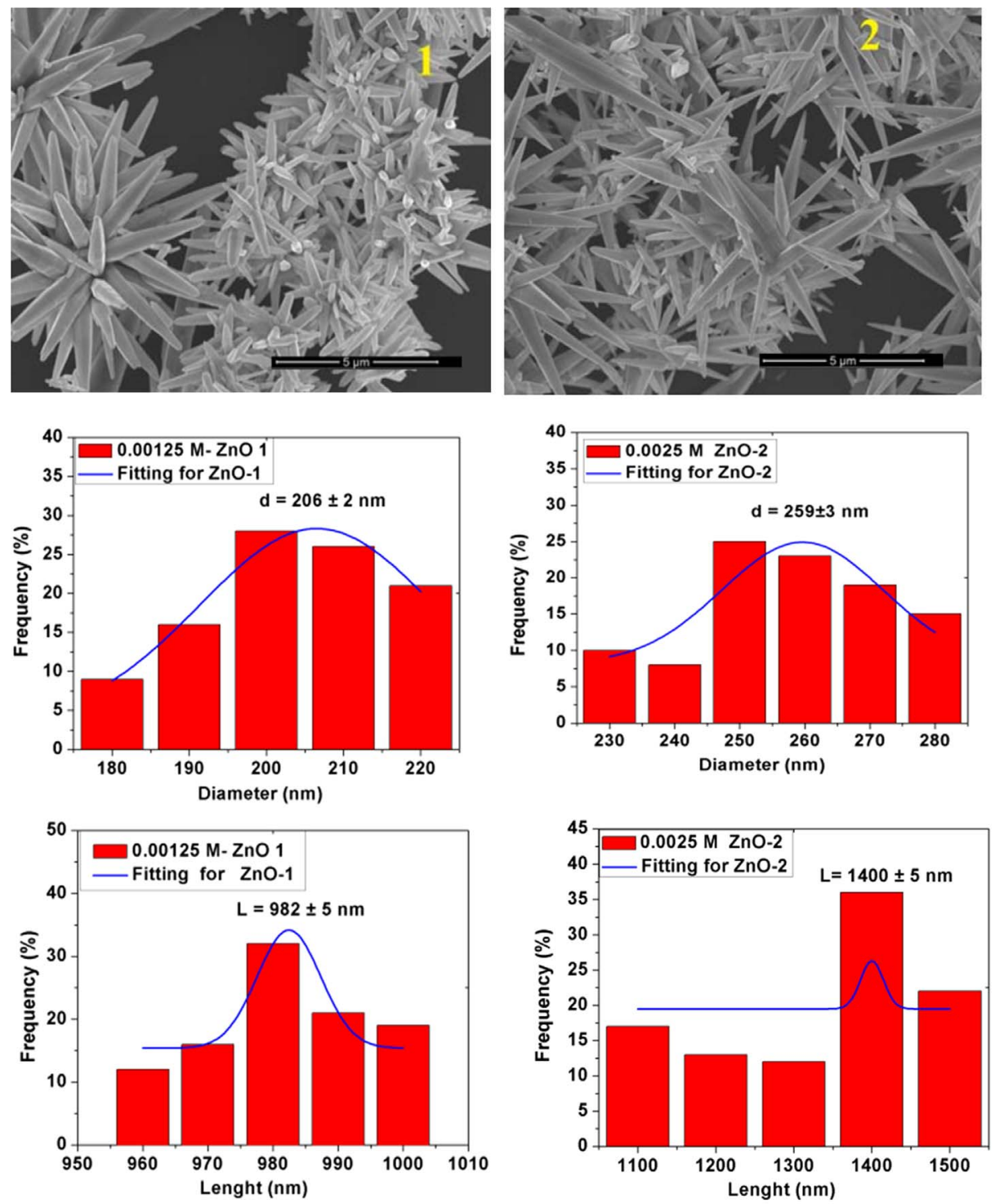
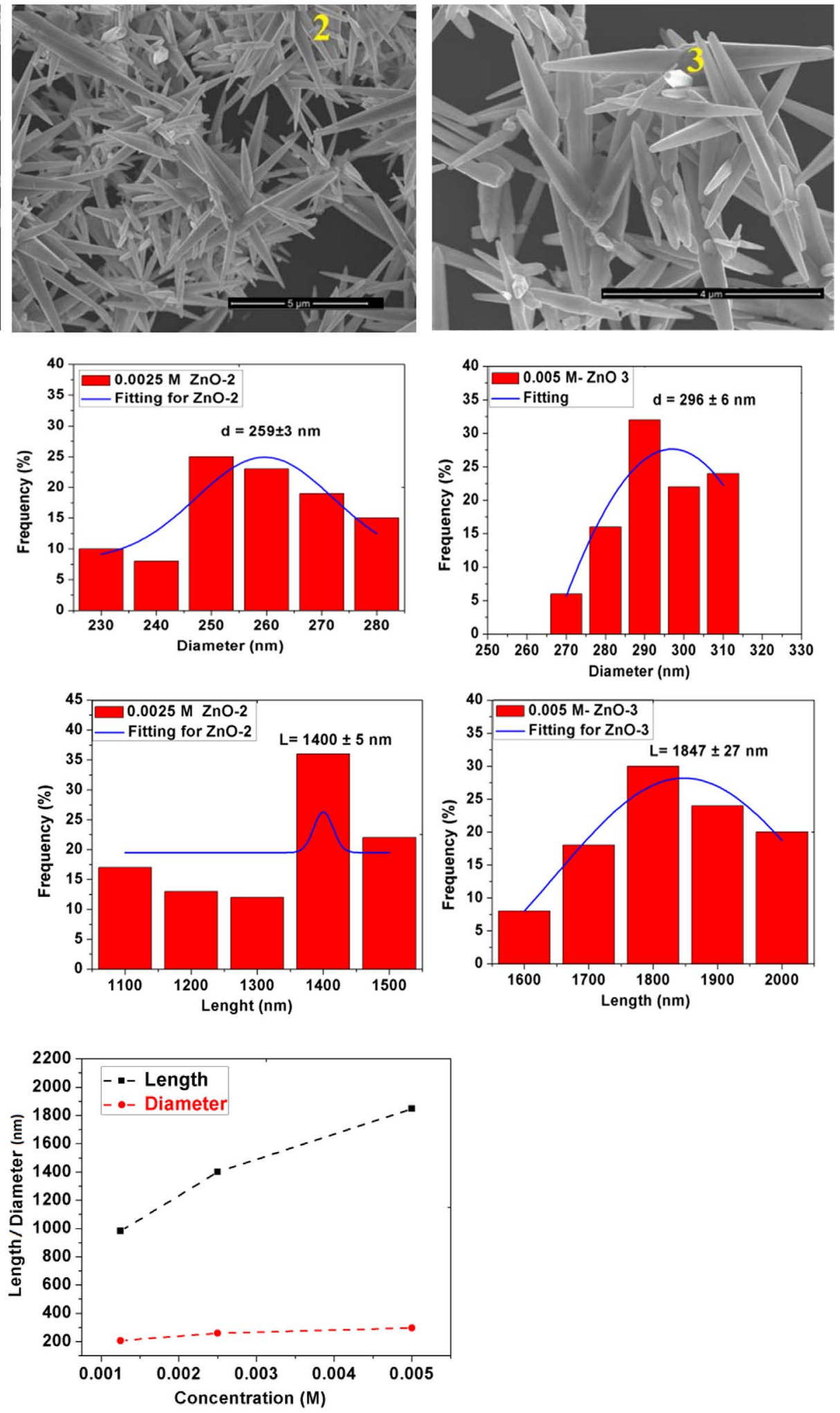

Fig. 2. Diameter and length distribution of the varying concentrations of the precursors for $\mathrm{ZnO}-1$, $\mathrm{ZnO}-2$ and $\mathrm{ZnO}-3$ for $95{ }^{\circ} \mathrm{C}$.

(intermediate) plays a role in the condensation and particle formation process. By utilization of the surface directing agents such as HMTA or some other amines, hydrolysis and condensation reactions of zinc salts result in one-dimensional $\mathrm{ZnO}$ nano crystals. Observations revealed that wire shaped structures were formed at $\mathrm{pH}>9$ and this process does not additional additives. Additionally basic conditions are vitally important since divalent metal cations do not readily hydrolyze in acidic media and form necessary structures. It has been suggested [19] that additives like HMTA decomposes during the reaction and increases the $\mathrm{pH}$ to above 9 at the crystal surface and therefore acts as promoters or inhibitors for nucleation and growth. In a similar study it has been revealed that counter ions like nitrate, acetate, chloride, formate, sulphate modulate the morphology of the fabricated $\mathrm{ZnO}$ crystals but concentration, zinc to HMTA proportion, method, sub- 


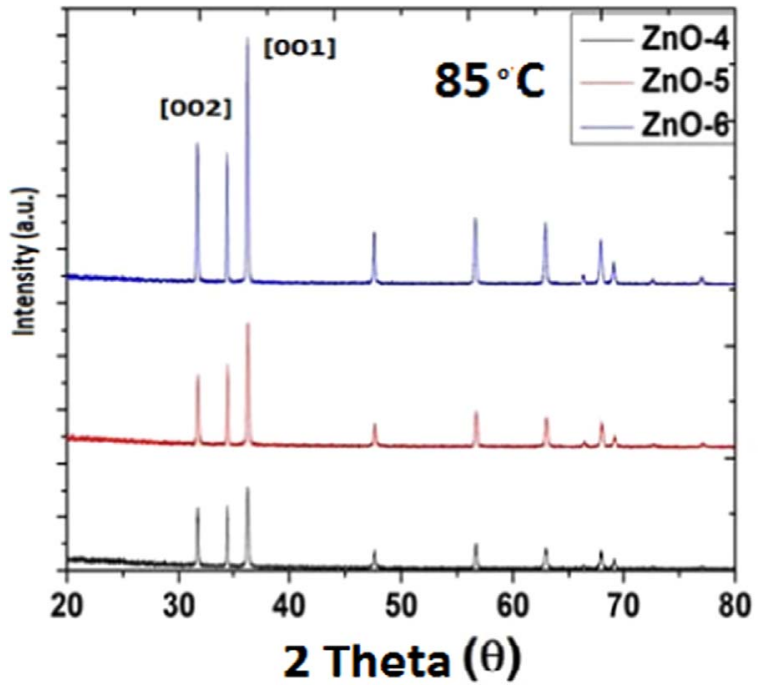

Fig. 3. XRD patterns of $1 \mathrm{D} \mathrm{ZnO}$ structures obtained with different concentration proportions at $85{ }^{\circ} \mathrm{C}$.

strate features and synthesis conditions were completely different [15]. In previous studies hydrolysis of zinc nitrate resulted that HMTA concentrations should be less than $0.1 \mathrm{M}$ within the $5<\mathrm{pH}<8$ and especially temperature should be $>80^{\circ} \mathrm{C}$ for a regular elongated $\mathrm{ZnO}$ species. HMTA is a nonionic cyclic tertiary amine and acts as a Lewis base which capable of bidentate complex formation with two zinc(II) ions in solution [20-25]. Additionally its hydrolysis produces suitable conditions and formaldehyde and ammonia in the necessary $\mathrm{pH}$ range. It is also known that HMTA and ammonia can kinetically control species in aqueous solution by the help of coordinated zinc(II). If concentration in the $\mathrm{ZnO}$ formation is low this allows us the opportunity of the selective growth for the selected precursors [20-24].

\subsection{Effects of concentration on the $\mathrm{ZnO}$ nanorod formation}

Fig. 1a describes the formation of $1 \mathrm{D} \mathrm{ZnO}$ and attachment of the HMTA for the growth reactions. Concentration effect on the growth of the $\mathrm{ZnO}$ nano-micro structures were analysed by XRD (Fig. 1b) and SEM (Fig. 2). ZnO-1 represents the highest concentration in the denotation. Chemical reactions and equations which are anticipated during the formation of the $\mathrm{ZnO}$ structures were presented by Eqs. (1)(5).

$\mathrm{HMTA}+6 \mathrm{H}_{2} \mathrm{O} \rightleftharpoons \mathrm{NH}_{3}+6 \mathrm{HCOH}$

$\mathrm{NH}_{3}+\mathrm{H}_{2} \mathrm{O} \rightleftharpoons \mathrm{NH}_{4}^{+}+\mathrm{OH}^{-}$

$\mathrm{Zn}^{2+}+4 \mathrm{NH}_{3} \rightleftharpoons\left[\mathrm{Zn}\left(\mathrm{NH}_{3}\right)_{4}\right]^{2+}$

$\mathrm{Zn}^{2+}+2 \mathrm{OH}^{-} \rightleftharpoons \mathrm{Zn}(\mathrm{OH})_{2}$

$\mathrm{Zn}(\mathrm{OH})_{2} \rightleftharpoons \mathrm{ZnO}+\mathrm{H}_{2} \mathrm{O}$

When concentration effect on the growth and crystallinity is compared, XRD results showed that at $95{ }^{\circ} \mathrm{C}$ there is no big difference on the specific facets of the $\mathrm{ZnO}$ nano-micro rods. Especially in [002] peaks which correspond to the $c$ axis, similarity is seen between the $5 \times 10^{-3} \mathrm{M} \quad(\mathrm{ZnO}-1)$, and $2.5 \times 10^{-3} \mathrm{M} \quad(\mathrm{ZnO}-2)$ together with $1.25 \times 10^{-3} \mathrm{M}(\mathrm{ZnO}-3)$ concentrations of zinc salt and HMTA. Other [100] and [001] peaks show the analog behavior. This results revealed that it is possible to use the lowest $\left(1.25 \times 10^{-3} \mathrm{M}\right)$ concentration of the zinc salt and HMTA for the synthesis of $\mathrm{ZnO}$ nano-micro rods. Analysis of the SEM images provided detailed information about the obtained structures at this concentration. SEM images of the highest 1:1 concentration ( $\mathrm{ZnO}-1)$ reveals cone shape of the elongated nano-micro $\mathrm{ZnO}$ structures. Different size and diameter distribution was detected which may form due to the small regional concentration fluctuations.

Results showed that generally decreasing precursor concentration slightly increases the diameter and length of the $\mathrm{ZnO}$ structures obtained but some variations can be observed. In higher concentrations of the precursor, $\mathrm{ZnO}$ structures formed urchin like branched morphology and as the concentration decreased, longer and less branched $\mathrm{ZnO}$ cones are observed. Generally cone structures becomes dominant and branches disappear. It can be observed that if concentration decreases, appeared XRD peaks are less in their intensity and (001)/ (002) ratio decreases too. All the obtained XRD diffraction patterns showed no different peaks from the JCPDS card number 36-1451. The peaks in the XRD spectra could be assigned to the (100), (002), (101), (102), (110), (103), (112), and (004) crystal planes of $\mathrm{ZnO}$ nanorods with wurtzite crystal structure respectively.

1D $\mathrm{ZnO}$ structures (nano-micro rods) showed conical shape and they are well-ordered but (002) XRD peak is not the most highest in intensity which shows that the growth pattern is not exactly along the c-axis direction. SEM images proved that elongated structures form urchin type structures which broader side attach together. Additionally aggregation and attachment of tail-to-tail is visible. Dimensional comparison with different concentrations have been summarized in Fig. 3. By combining the SEM results, it is clear that increasing concentration increases the length and diameter of the nanorods. Variation in the diameter is slightly smaller but it is also changing with different concentrations. Due to its nano/micro regime dimensions, lower agglomeration, less bi or multimodal morphology variation and sustainable conical morphology, lowest concentration can be Utilized for the fabrication of $1 \mathrm{D} \mathrm{ZnO}$ structures. These acicular morphology under micrometer range seems forming almost no urchin type structures providing better dispersibility and easy to measure characteristics.

\subsection{Effect of the temperature on the $1 \mathrm{D} \mathrm{ZnO}$ formation}

After the analysis of the concentration effect for the formation of 1D dimensional $\mathrm{ZnO}$ structures controlled by counter $\mathrm{NO}_{3}{ }^{-}$anion, in the next step, temperature parameter was investigated. Therefore same three concentration were used but temperature was decreased to $85^{\circ} \mathrm{C}$. Again, all the obtained XRD diffraction patterns showed no different peaks from the JCPDS card number 36-1451 (Fig. 3). According to the literature, when $\mathrm{Zn}\left(\mathrm{NO}_{3}\right)_{2} \cdot 6 \mathrm{H}_{2} \mathrm{O}$ is used as the precursor together with HMTA, obtained structures were rod-shaped whereas $\mathrm{ZnCl}_{2}$ resulted with acicular morphology. It should be noted that temperature, concentration, volume and some other parameters are always different and these results therefore only can give a rough anticipation about the 1D $\mathrm{ZnO}$ structure fabrication.

It was found that $\mathrm{Zn}^{2+}$ cation and other available species form some intermediate molecules like $\mathrm{Zn}_{5} \mathrm{Cl}_{2}(\mathrm{OH})_{8}$ in the $\mathrm{ZnCl}_{2}$ case and decrease in $\mathrm{pH}$ value can form the individual needles or prismatic microcrystals. According to XRD patterns in Fig. 3 (001) peak shows its highest intensity in the lowest $(0.00125 \mathrm{M})$ concentration. Interestingly if concentration is changed to $0.0025 \mathrm{M}(\mathrm{ZnO}-5)$ and $0.005 \mathrm{M}(\mathrm{ZnO}-4)$, $(001) /(002)$ peak ratio decreases remarkably. Especially at this temperature $\left(85^{\circ} \mathrm{C}\right)$ when concentration is $0.00125 \mathrm{M}(\mathrm{ZnO}-4)$ highest (002) intensity is observed. Additionally size and diameter investigation of the obtained 1D nanostructures (Fig. 4) were also conducted.

According to the results presented in Fig. 4, diameter of the $1 \mathrm{D} \mathrm{ZnO}$ nano/micro structures do not show a remarkable morphology variation. Fluctuations are about $\pm 15 \mathrm{~nm}$ when we compare these three ( $\mathrm{ZnO}-4$, $\mathrm{ZnO}-5, \mathrm{ZnO}-6)$ structures. On the other hand if we analyze the average length values, we observe a non uniform variation. At low concentrations of $\mathrm{Zn}\left(\mathrm{NO}_{3}\right)_{2} \cdot 6 \mathrm{H}_{2} \mathrm{O}: \mathrm{HMTA}(1: 1)$ mixture, $3270 \mathrm{~nm}$ average value for the obtained $1 \mathrm{D} \mathrm{ZnO}$ structures were detected but this value was decreased to $3030 \mathrm{~nm}$ when the concentration was increased two-fold. Interestingly again, at highest $0.005 \mathrm{M}$ concentration, average length value was increased to a point $(3206 \mathrm{~nm})$ similar to $\mathrm{ZnO}-4$. 

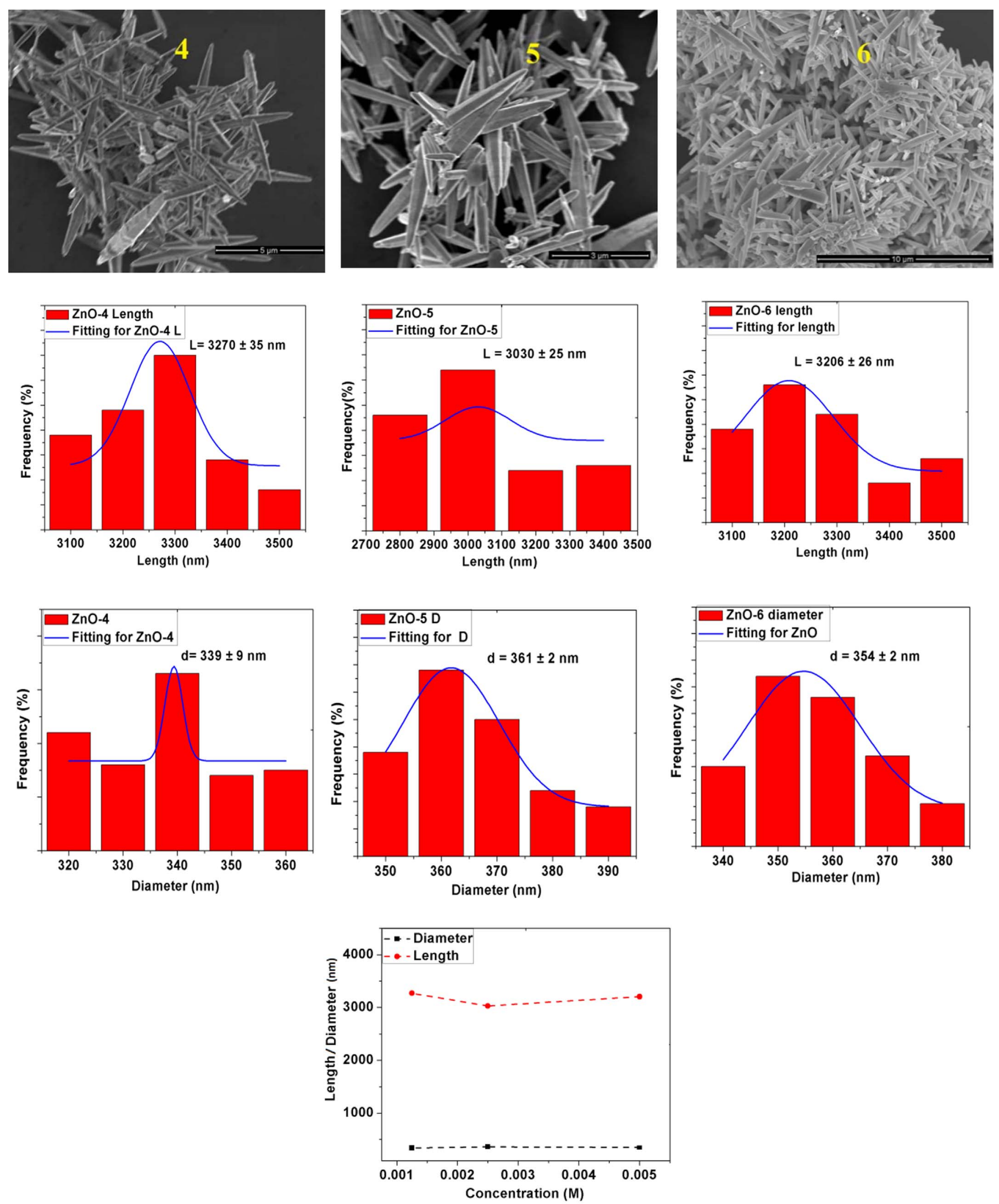

Fig. 4. Diameter and length distribution of the varying concentrations of the precursors for $\mathrm{ZnO}-4$, $\mathrm{ZnO}-5$ and $\mathrm{ZnO}-6$ for $85{ }^{\circ} \mathrm{C}$.

In Fig. 5a temperature effect on the crystallinity between the range of $55{ }^{\circ} \mathrm{C}$ and $95{ }^{\circ} \mathrm{C}$ is observed with $0.00125 \mathrm{M}$ precursor values. Concentration was kept similar but when the temperature was decreased to $55{ }^{\circ} \mathrm{C}$ it is clear that crystallinity of the obtained $\mathrm{ZnO}$ nanostructures was remarkably low and almost no crystalline structures were observed (Fig. 5c). Morphological observation of the same 

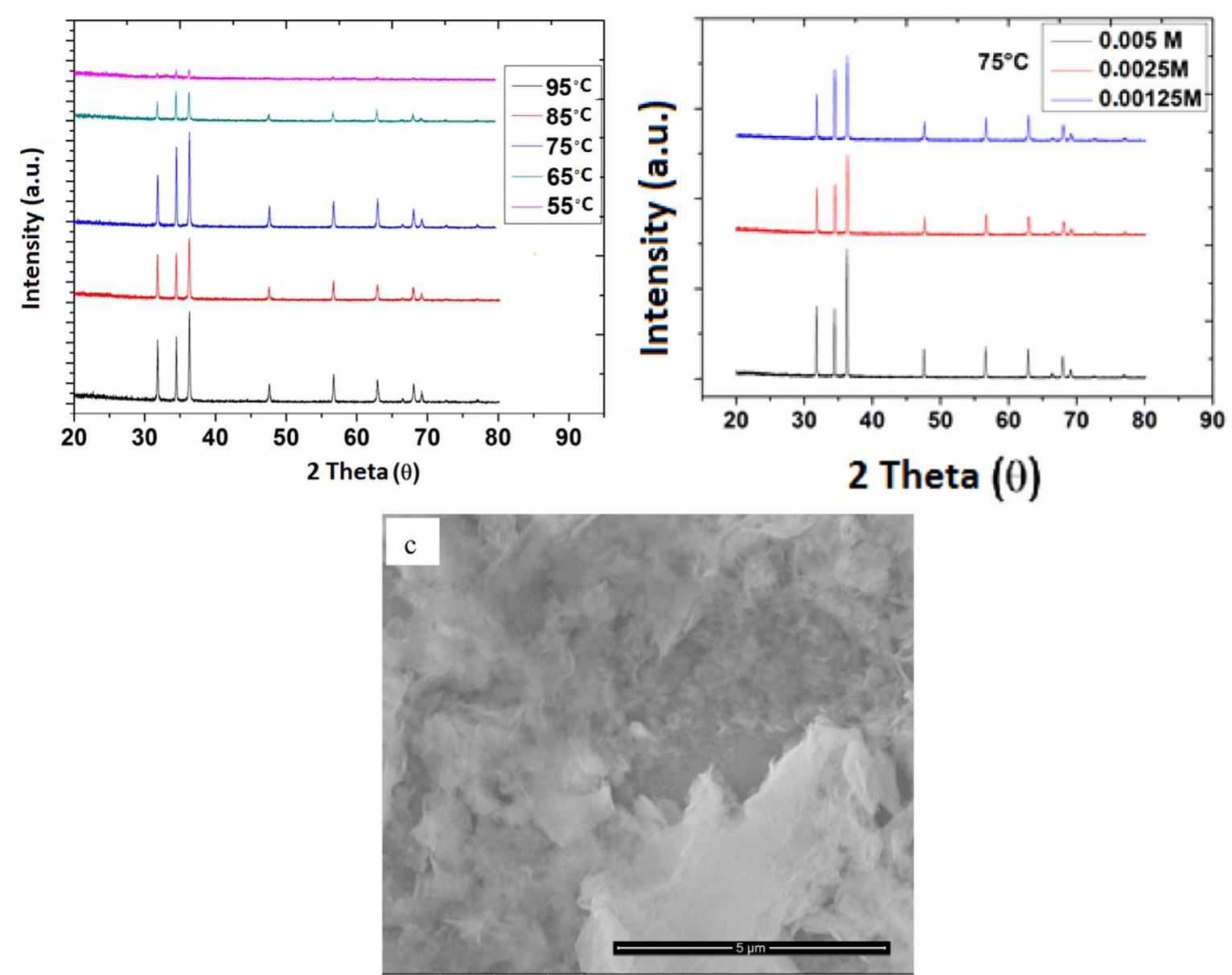

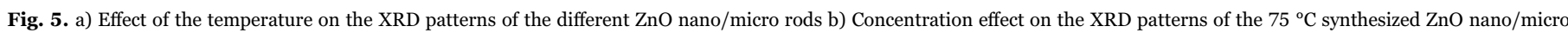
rods c) SEM image for the $\mathrm{ZnO}$ structures obtained at $55^{\circ} \mathrm{C}$.

phenomena can also be monitored by SEM pictures for $75{ }^{\circ} \mathrm{C}, 65^{\circ} \mathrm{C}$ and $55^{\circ} \mathrm{C} .75^{\circ} \mathrm{C}$ is still efficient for the formation of the $1 \mathrm{D} \mathrm{ZnO} \mathrm{nano/}$ micro structures as XRD patterns showed at different concentrations (Fig. 5b). But at $65^{\circ} \mathrm{C}$, instead of the [001] facet, [002] becomes more dominant and at $55{ }^{\circ} \mathrm{C}$ not an XRD peak pattern was observed. SEM pictures for $55{ }^{\circ} \mathrm{C}$ showed that there is no $1 \mathrm{D} \mathrm{ZnO}$ formation and relatively bulk structures are seen (Fig. 5 c).

\subsection{Surface and optical properties of the $1 \mathrm{D} \mathrm{ZnO} \mathrm{nano/micro}$ structures}

XPS was used to investigate the surface composition of the obtained $\mathrm{ZnO}$ nanorods. For investigation of the $1 \mathrm{D} \mathrm{ZnO}$ surfaces, $\mathrm{ZnO}-3$ was selected as model structure. Fig. 6 reveals the XPS survey and high resolution $\mathrm{O} 1 \mathrm{~s}, \mathrm{Zn} 2 \mathrm{p}$ and $\mathrm{N}$ 1s spectra. $\mathrm{N}$ 1s region was scanned with high resolution parameters to investigate if HMTA is still attached to the surface or any nitrogen is available on the $\mathrm{ZnO}$ surface.

As observed, there is no observable peak for the high resolution $\mathrm{N}$ 1s range. According to the survey spectra (Fig. 6a), all of the peaks can only be ascribed to $\mathrm{Zn}, \mathrm{O}$, and $\mathrm{C}$ elements as labeled. No other impurities were observed except $\mathrm{C}$ as impurity. All the XPS spectra was calibrated with the binding energy of carbon C1s peak $(284,7 \mathrm{eV})$ as reference. Thermo Avantage v4 programme was used for the raw data. The deconvolutions of the XPS peaks for the O1s core level line from washed/dried $\mathrm{ZnO} 1 \mathrm{D}$ nanorods are shown in Fig. 6b. In this figure, the deconvolutions show the presence of two different O1s peaks in the fabricated $1 \mathrm{D} \mathrm{ZnO}$ structures. The peak centered at $531.4 \mathrm{eV}$ (O1) is associated to the $\mathrm{Zn}$ bonded oxygen in the wurtzite nanostructure surrounded by the $\mathrm{Zn}$ metal atoms with their full complement of nearest-neighbor O2- ions. Additionally peak at $533.6 \mathrm{eV}$ is attributed to the presence of $\mathrm{OH}$ bonds, i.e. $\mathrm{ZnO}(\mathrm{OH})$. High resolution XPS spectra of the $\mathrm{Zn}$ atom was shown in Fig. 6c. The deconvolutions of the $\mathrm{Zn} 2 \mathrm{p}$ spectra showed that $\mathrm{Zn} 2 \mathrm{p} 3 / 2$ and $\mathrm{Zn} 2 \mathrm{p} 1 / 2$ peaks are positioned on 1021.2 and $1044.6 \mathrm{eV}$ respectively. Obtained peaks are asymmetrical, densities are different and peaks are relatively broad. For a good fit to the experimental data, we have applied the deconvolutions of two Gaussians for the spectras. It can be speculated that almost same type of $\mathrm{Zn}$ species exist on the surface of the $\mathrm{ZnO}$ nanorods. The observed peak with binding energy of 1021.2 is associated to $\mathrm{Zn}$ species in $\mathrm{ZnO}$ but very small fluctuation around the binding energy of $1022 \mathrm{eV}$ could correspond to $\mathrm{Zn}$ in $\mathrm{ZnO}(\mathrm{OH})$ but there is no clarity on this issue.

Fig. 7 shows the TEM and HR-TEM images of the ZnO-3. From images we can see the diameter of the $1 \mathrm{D} \mathrm{ZnO}$ structure is around $2 \mu \mathrm{m}$ and crystallinity is high. In HR-TEM, it is possible to observe the [002] $\mathrm{d}$-d spacing as $0.26 \mathrm{~nm}$ with $2 \mathrm{~nm}$ scale bar. Images reveal that $1 \mathrm{D} \mathrm{ZnO}$ structures have high crystal orientation throughout the structure. As interplanar spacing also confirmed, $\mathrm{ZnO}$ growth and crystallinity are consistent with the speculated experimental results.

FT-IR results (Fig. 8a) of the Zn precursor and elongated final $\mathrm{ZnO}$ structure revealed the pure and clean surface. Peak at $540 \mathrm{~cm}-1$ belongs to the $\mathrm{Zn}-\mathrm{O}$ and at $3300 \mathrm{~cm}-1$ belongs to the water $(-\mathrm{OH})$ peak in the zinc precursor. Spectra shows no residue of the HMTA adsorption or any other organic molecules on the final 1D $\mathrm{ZnO}$. Complex fingerprint peaks of the HMTA is quite characteristic and generally belong to the $\mathrm{N}-\mathrm{H}$ or $\mathrm{N}-\mathrm{C}$ bonding. But final structure does not contain any of these peaks proving a clear $\mathrm{ZnO}$ surface. Fig. 8b reveals the temperature effect on UV-vis absorption spectras of the $1 \mathrm{D}$ 

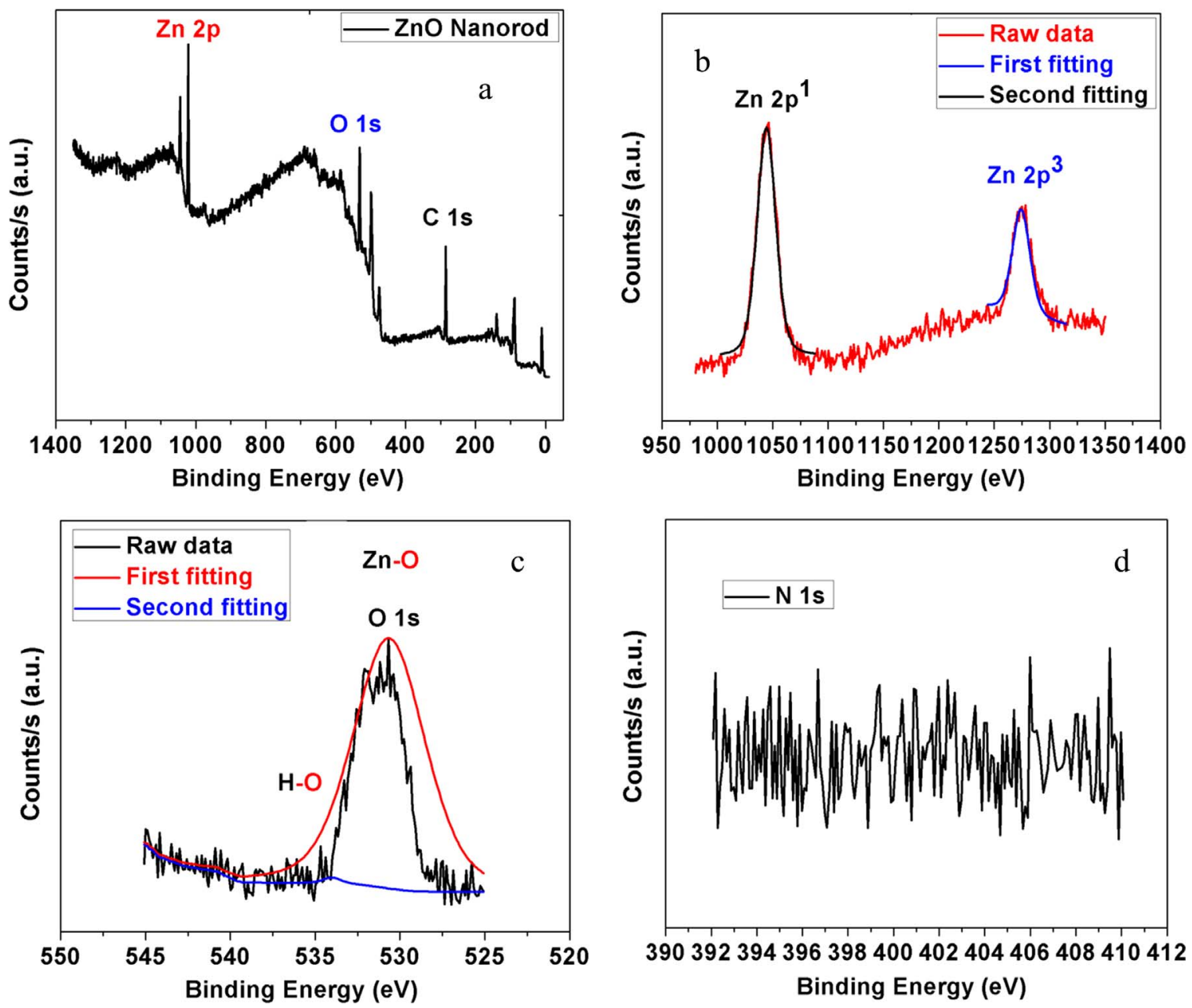

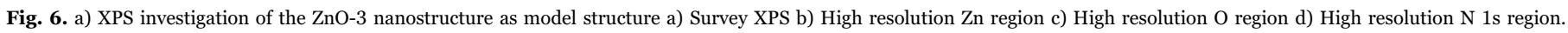
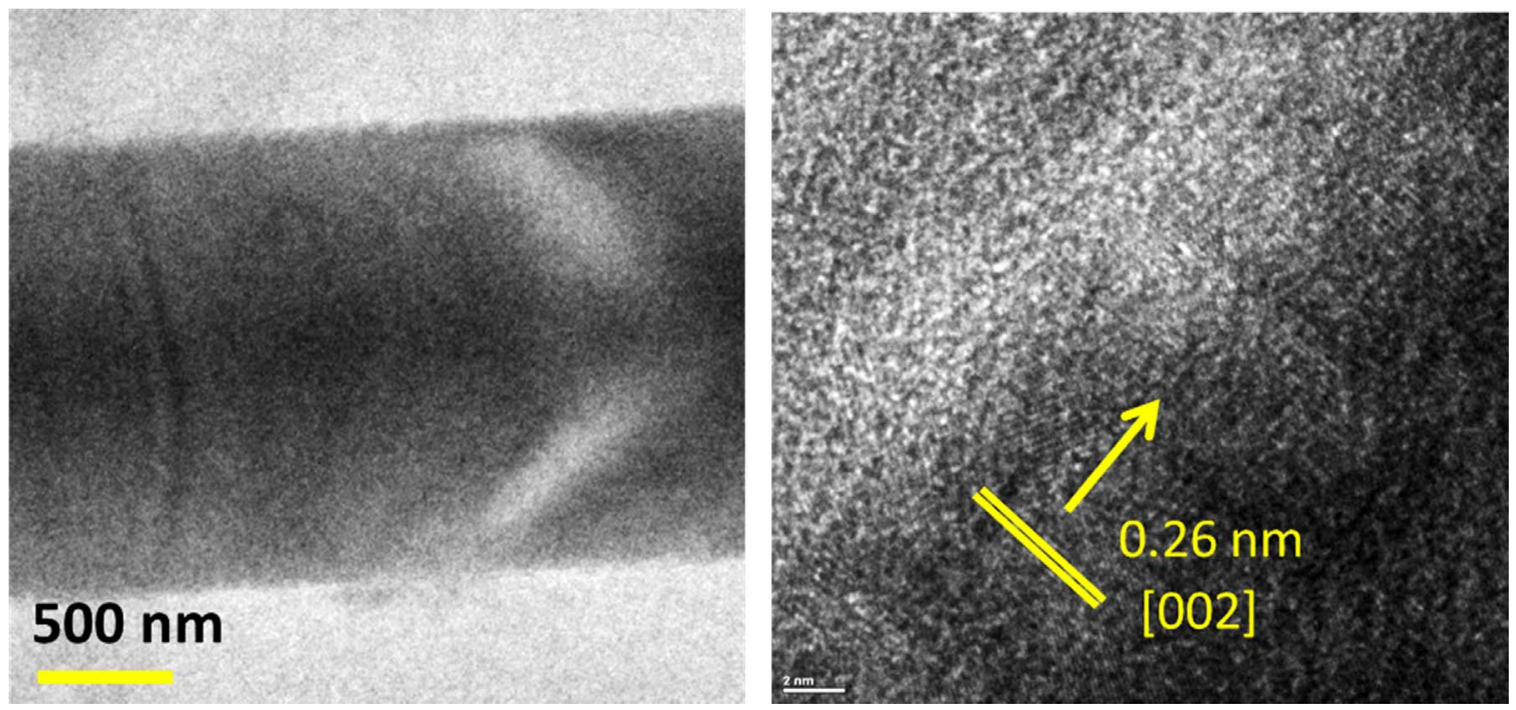

Fig. 7. TEM and HR-TEM investigation with [002] spacing measurements for $\mathrm{ZnO}-3$.

$\mathrm{ZnO}$ nano/micro structures. It is widely known that optical absorption edge has a tendency to shift upper or lower wavelengths with variation in growth temperature, concentration and other counter ions. According to the UV-vis absorption spectra maximum point of the absorption is around $394 \mathrm{~nm}$ and relatively broad as seen in the Fig. 8b. Interestingly UV absorption peak for $65^{\circ} \mathrm{C}$ showed a very small absorption maximum but $55{ }^{\circ} \mathrm{C}$ shows almost no absorption. This is also another effect of the temperature on the $1 \mathrm{D} \mathrm{ZnO}$ formation under mentioned conditions. Zeta potential measurement was conducted for $\mathrm{ZnO}-3$ to investigate the surface character in aqueous conditions. At very neutral conditions $(\mathrm{pH}=6.9)$ synthesized structures gave an average $-34 \mathrm{mV}$ (Fig. 8c) value which means a negatively loaded $\mathrm{ZnO}$ surface structure in water. Possibly oxygen dominant composition and utilized precursors provided measured value. 

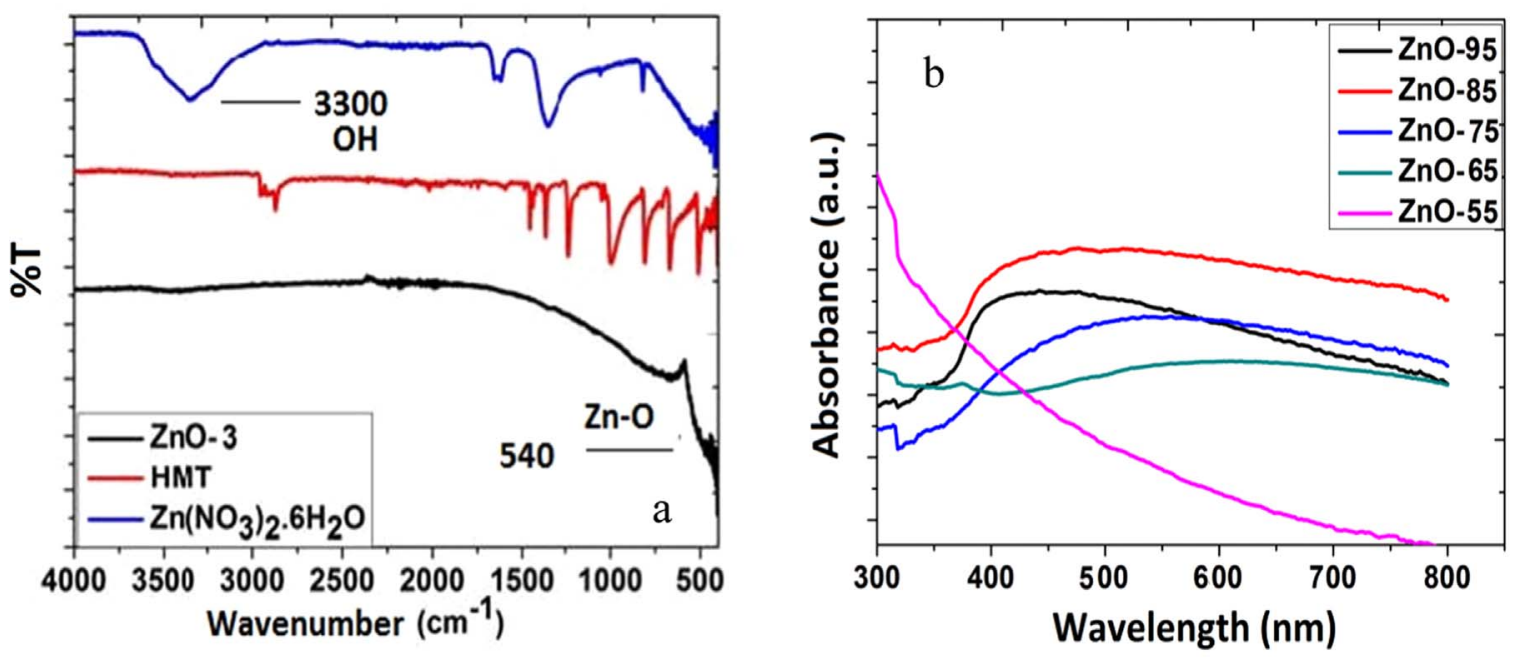

Zeta Potential Distribution

C

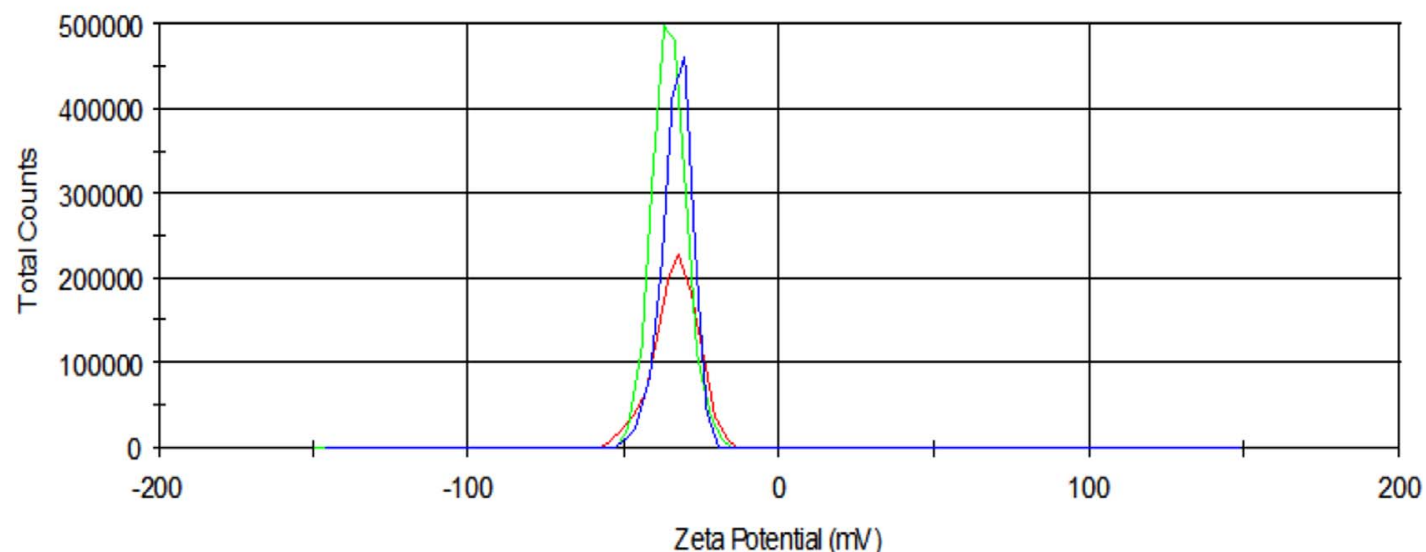

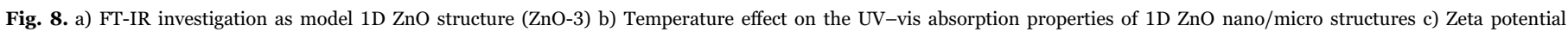
measurement $(-34 \mathrm{mV})$ of the $\mathrm{ZnO}-3$ at $\mathrm{pH}=6.9$.

Investigation of the photocatalytic activities of as-synthesized 1D $\mathrm{ZnO}$ structures were conducted on degradation of the methylene blue (MB). Beginning concentration $\left(\mathrm{C}_{0}\right)$ of $\mathrm{MB}$ solution was analysed by the maximum absorption peak at about $662 \mathrm{~nm}(\lambda \max )$ by UV-vis spectroscopy. As stated earlier, in every experiment adsorption of the MB was excluded to derive the exact value of the decomposition degree. If there was no UV light irradiation, beginning concentration of $\mathrm{MB}$ was unchanged (not shown here). In Fig. 9 variation of degradation processes with the assistance of $1 \mathrm{D} \mathrm{ZnO}$ nano-micro structures were presented. Obviously a continuous decrease of $\mathrm{MB}$ absorption by increasing irradiation time was observed. Additionally no new peak observed during the decomposition process indicating the degradation of possible intermediate products. In Fig. 9 photocatalytic degradation of $\mathrm{MB}$ was presented as a function of irradiation time with different $1 \mathrm{D}$ $\mathrm{ZnO}$ nano/micro structures. According to the continuous degradation of the $\mathrm{MB}$, it can be revealed that degradation of $\mathrm{MB}$ can be described by Langmuir-Hinshelwood mechanism. In this equation $\mathrm{C}_{0}$ is initial concentration of used $\mathrm{MB}, \mathrm{C}$ is the concentration of $\mathrm{MB}$ depending on irradiation time, and $\mathrm{k}$ is reaction rate constant. Therefore if there is an increase in $-\operatorname{In}\left(\mathrm{C} / \mathrm{C}_{0}\right)$ this will correspond to a decrease in the degradation of $\mathrm{MB}$. It is clear that $\mathrm{ZnO}-3$ and 4 shows the best activity and decomposed about $96-97 \%$ of MB after 90 min irradiation. When compared to other obtained $\mathrm{ZnO}$ structures, $\mathrm{ZnO}-5$ shows the weakest photocatalytic activity. Supporting Table 1, presents the decomposition rates of the methylene blue with fabricated $\mathrm{ZnO}$ structures. When kinetic behaviors of these $1 \mathrm{D} \mathrm{ZnO}$ structures studied, an obvious linear relationship between the value of $\ln \left(\mathrm{C}_{0} / \mathrm{C}\right)$ and the irradiation time can be observed with slight variations. Whole photocatalytic process can be regarded as pseudo first-order reaction obeying the presented expression. According to the results $\mathrm{ZnO}-4$ has the highest $\mathrm{k}$ constant with $8.2 \times 10^{-3} \mathrm{~min}^{-1}$ value which was also noticeable during the experimental conditions. Accordingly $\mathrm{ZnO}$ structures which were obtained at $55^{\circ} \mathrm{C}$ and $65^{\circ} \mathrm{C}$ were not compared since their observation is speculative due to the low crystalline character.

Additionally $\mathrm{ZnO}-1$ and $\mathrm{ZnO}-2$ showed relatively weak photocatalytic efficiency. After a thoroughly investigation, it can be concluded that reasons such as; a) local agglomerations, b)lower surface area due to the urchin type 1D $\mathrm{ZnO}$ structure formation c) bigger size/lower adsorption (decomposition) capacity can be the reason for the lower activity. Especially SEM images clearly support this estimation. Since lower agglomeration and higher adsorption of the dye and higher surface area is available for the $\mathrm{ZnO}-3$, decomposition values are better as compared to other structures. Same derivatization can be done for the $\mathrm{ZnO}-4$. $\mathrm{ZnO}-6$ also shows also an efficient photoactivity $(92 \%$ decomposition) while blank samples are almost remained unaffected. Comparing the activity results we can simply conclude that the photocatalytic activity is affected by different parameters for the formation of $1 \mathrm{D} \mathrm{ZnO}$ nano-micro structures.

Temperature effect onto the obtained $\mathrm{ZnO}$ nano/micro structures can be seen at Fig. 9c. It was observed that $\mathrm{ZnO}$ nano/micro structure photocatalytic efficiency was relatively poor when compared to previous compositions. Especially photocatalytic efficiency test for the $\mathrm{ZnO}$ nano/micro structures obtained at $65{ }^{\circ} \mathrm{C}$ and $55{ }^{\circ} \mathrm{C}$ resulted with very low values. Probably low crystallinity caused no efficiency and obtained 

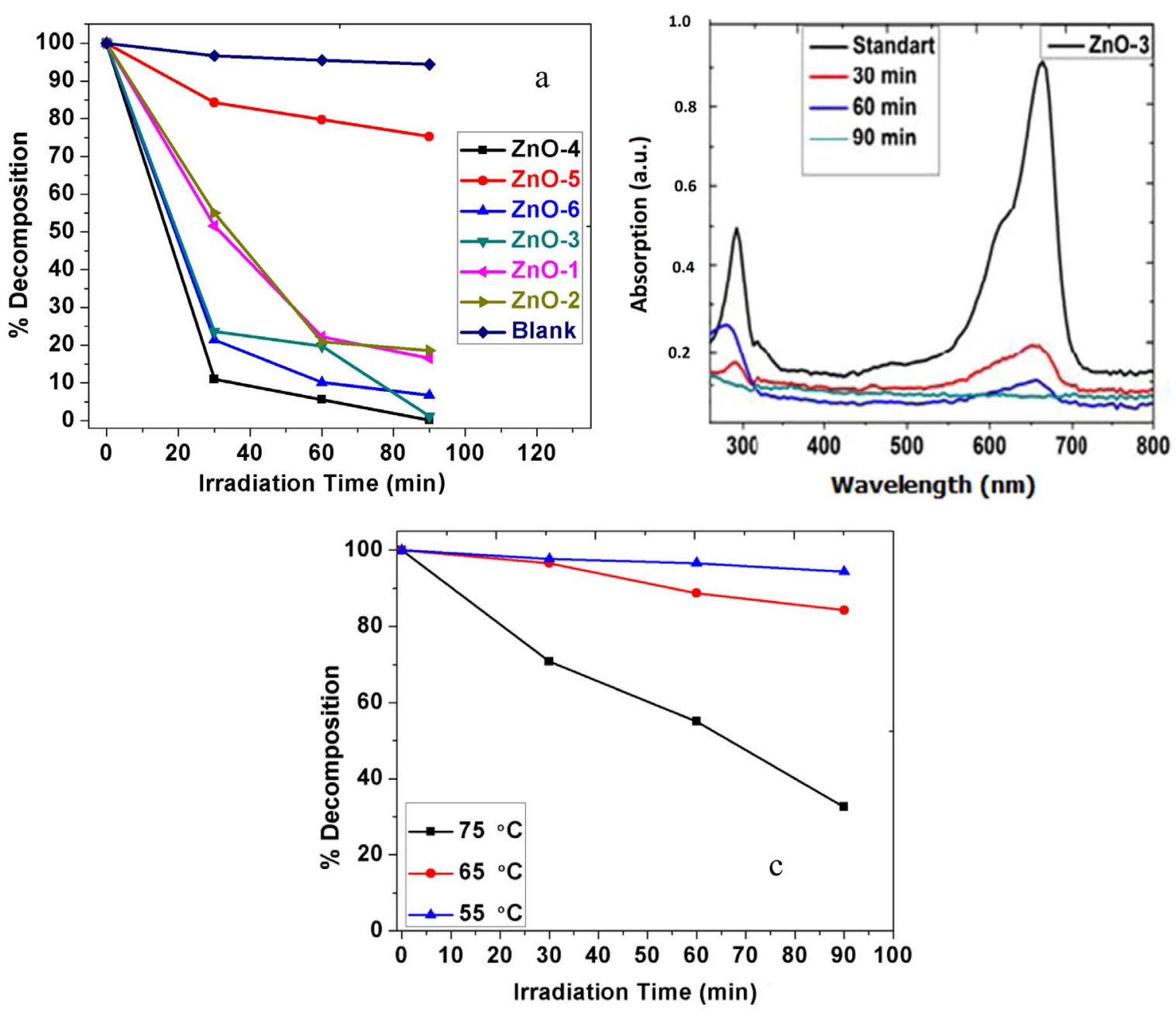

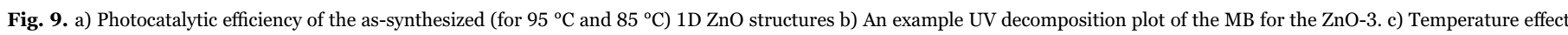
onto the photocatalytic evaluation of the $\mathrm{ZnO}$ structures obtained at $75{ }^{\circ} \mathrm{C}, 65{ }^{\circ} \mathrm{C}$ and $55{ }^{\circ} \mathrm{C}$.

results are the adsorption of the $\mathrm{MB}$ dye onto the $\mathrm{ZnO}$ structures.

As a results, we have revealed that, temperature has an enormous effect on the formation of surfactant facilitated $1 \mathrm{D} \mathrm{ZnO}$ structures. Crystallinity and optical properties together with morphological and surface characteristics showed that, highly crystalline structures can be obtained till $75{ }^{\circ} \mathrm{C}$ under the mentioned conditions. After this temperature, possibly there is no enough energy for the aligned growth of the $\mathrm{ZnO}$ nano/micro structures. Instead, amorphous geometries were observed. XPS spectroscopy and TEM investigation proved that surface contain no HMTA agent which is a clear proof for the formation of clean and catalytically active $1 \mathrm{D} \mathrm{ZnO}$ structures.

\section{Conclusion}

Results for the formation of the $\mathrm{ZnO}$ structures have showed that temperature and concentration have a huge effect on the growth habits of the elongated $\mathrm{ZnO}$ nano/micro structures as analytical analysis revealed. Specific intensity increase in [001] XRD peak was observed in the decreased temperature with lowest concentration of the reacting species. Slightly nano/micrometer sized structures or cone shaped structures with urchin type formations were observed. XPS results revealed no nitrogen availability and decomposition results showed varying decomposition profiles for as-synthesized $\mathrm{ZnO}$ structures. Temperature examination revealed that under low temperature conditions $\left(55^{\circ} \mathrm{C}\right)$ crystal formation was not observed and photocatalytic activity was also inefficient.

\section{Acknowledgment}

Dr. Arslan gratefully acknowledges the Celal Bayar University for infrastructure and The Scientific \& Technological Research Council of Turkey (TUBITAK), BIDEB Fellowships for 2232 programme (project no. 115C095).

\section{Appendix A. Supporting information}

Supplementary information associated with this article can be found in the online version at doi:10.1016/j.jpcs.2017.04.017.

\section{References}

[1] D.C. Reynolds, D.C. Look, B. Jogai, C.W. Litton, T.C. Collins, W. Harsch, G. Cantwell, Neutral-donor-bound-exciton complexes in ZnO crystals, Phys. Rev. B 57 (1998) 12151-12155.

[2] M. Law, J. Goldberger, P.D. Yang, Semiconductor nanowires and nanotubes, Annu. Rev. Mater. Res. 34 (2004) 83-122.

[3] M.H. Huang, S. Mao, H. Feick, H.Q. Yan, Y.Y. Wu, H. Kind, E. Weber, R. Russo, P.D. Yang, Room-temperature ultraviolet nanowire nanolasers, Science 292 (2001) 1897-1899.

[4] J. Goldberger, D.J. Sirbuly, M. Law, P.J. Yang, ZnO nanowire transistors, Phys. Chem. B 109 (2005) 9-14.

[5] H. Kind, H.Q. Yan, B. Messer, M. Law, P.D. Yang, Nanowire ultraviolet photodetectors and optical switches, Adv. Mater. 14 (2002) 158-160.

[6] Q. Wan, Q.H. Li, Y.J. Chen, T.H. Wang, X.L. He, J.P. Li, C.L. Lin, Fabrication and ethanol sensing characteristics of $\mathrm{ZnO}$ nanowire gas sensors, Appl. Phys. Lett. 84 (2004) 3654-3656.

[7] M. Law, L.E. Greene, J.C. Johnson, R. Saykally, P.D. Yang, Nanowire dye-sensitized solar cells, Nat. Mater. 4 (2005) 455-459. 
[8] N.S. Norberg, K.R. Kittilstved, J.E. Amonette, R.K. Kukkadapu, D.A. Schwartz, D.R. Gamelin, Synthesis of colloidal $\mathrm{Mn}^{2+}: \mathrm{ZnO}$ quantum dots and high- $\mathrm{T}_{\mathrm{C}}$ ferromagnetic nanocrystalline thin films, J. Am. Chem. Soc. 126 (2004) 9387-9398.

[9] P.W. Tasker, The stability of ionic crystal surfaces, J. Phys. C: Solid State Phys. 12 (1979) 4977-4984.

[10] X.M. Chen, Y. Ji, X.Y. Gao, X.W. Zhao, Ag-doped ZnO nanorods synthesized by two-step method, Chin. Phys. B. 21 (2012) 116801.

[11] G. Kenanakisa, M. Androulida, E. Koudoumas, C. Savvakis, N. Katsarakis, Photoluminescence of $\mathrm{ZnO}$ nanostructures grown by the aqueous chemical growth technique, Superlattices Microstruct. 42 (2007) 473-478.

[12] E. Rokhsat, O. Akhavan, Improving the photocatalytic activity of graphene oxide/ ZnO nanorod films by UV irradiation, Appl. Surf. Sci. 371 (2016) 590-595.

[13] F.S. Chien, C.R. Wang, Y.L. Chan, H.L. Lin, M.H. Chen, R.J. Wu, Fast-response ozone sensor with $\mathrm{ZnO}$ nanorods grown by chemical vapor deposition, Sens. Actuators B 144 (2010) 120-125.

[14] L.W. Ji, S.M. Peng, Y.K. Su, S.J. Young, C.Z. Wu, W.B. Cheng, Ultraviolet photodetectors based on selectively grown $\mathrm{ZnO}$ nanorod arrays, Appl. Phys. Lett. 94 (2009) 203106.

[15] J.X. Wang, X.W. Sun, Y. Yang, H. Huang, H.Y. Lee, O.K. Tan, L. Vayssieres, Hydrothermally grown oriented $\mathrm{ZnO}$ nanorod arrays for gas sensing applications, Nanotechnology 17 (2006) 4995.

[16] W.I. Park, G.C. Yi, M.Y. Kim, S.J. Pennycook, ZnO nanoneedles grown vertically on Si substrates by non-catalytic vapor-phase epitaxy, Adv. Mater. 14 (2002) 1841-1843.
[17] J.J. Wu, S.C. Liu, Low-temperature growth of well aligned $\mathrm{ZnO}$ nanorods by chemical vapor deposition, Adv. Mater. 14 (2002) 215-218.

[18] P.D. Yang, H.Q. Yan, S. Mao, R. Russo, J. Johnson, R. Saykally, N. Morris, J. Pham, R.R. He, H. Choi, Controlled growth of $\mathrm{ZnO}$ nanowires and their optical properties, J. Adv. Funct. Mater. 12 (2002) 323-331.

[19] B.D. Yao, Y.F. Chan, N. Wang, Formation of $\mathrm{ZnO}$ nanostructures by a simple way of thermal evaporation, Appl. Phys. Lett. 81 (2002) 757-759.

[20] Y. Sun, G.M. Fuge, M.N.R. Ashfold, Growth of aligned ZnO nanorod arrays by catalyst-free pulsed laser deposition methods, Chem. Phys. Lett. 396 (2004) 21-26.

[21] L.E. Greene, M. Law, J. Goldberger, F. Kim, J.C. Johnson, Y.F. Zhang, R.J. Saykally, P.D. Yang, Low-temperature Wafer-scale production of ZnO nanowire arrays, Angew. Chem., Int. Ed. 42 (2003) 3031-3034.

[22] B.D. Yuhas, D.O. Zitoun, P.J. Pauzauskie, R. He, P. Yang, Transition-metal doped zinc oxide nanowires, Angew. Chem., Int. Ed. 45 (2006) 420-423.

[23] L.E. Greene, M. Law, D.H. Tan, M. Montano, J. Goldberger, G. Somorjai, P.D. Yang, General route to vertical $\mathrm{ZnO}$ nanowire arrays using textured $\mathrm{ZnO}$ seeds, Nano Lett. 5 (2005) 1231-1236.

[24] K. Govender, D.S. Boyle, P.B. Kenway, P.J. O’Brien, Understanding the factors that govern the deposition and morphology of thin films of $\mathrm{ZnO}$ from aqueous solution, Mater. Chem. 14 (2004) 2575-2591.

[25] H. Deyi, Z. Weili, G. Xiao, F. Yongming, H. Haoxuan, S. Jing, X. Lili, L. Baodan, $\mathrm{X}$. Xinyu, High piezo-photocatalytic efficiency of $\mathrm{CuS} / \mathrm{ZnO}$ nanowires using both solar and mechanical energy for degrading organic dye, ACS Appl. Mater. Int. 8 (2016) 21302-21314 